\title{
Infección por Bacilus Cereus en Recién Nacidos
}

\author{
Dr. Jacab Cohen $V,{ }^{1}$; Dra. Eliana Marambio L ${ }^{2}$; Dra. Beatriz Lynch $\mathrm{H}^{1}{ }^{1}$; Dr. Alberto Moreno M. ${ }^{3}$ \\ Bacillus Cereus in Food Poisoning Amid Newborns
}

\begin{abstract}
In a tood botne outbreak of diarrhea ocuring in a newbom unit and affecting 35 neonates, B. cereus was the only ethiological agent identified. Microbiological studies were pertiormed on the powdered milk used, on other samples of the same brand with different production dates and on other brands. Further studies were carried on formula bottles recently prepared and on those stored, at $4^{\circ} \mathrm{C}$ for 12 and $24 \mathrm{hrs}$. all were chosen at random. B. cereus was found to be the only ethiological agent identifiable in powdered milk and also in bottles, the amount of bacteria increasing with the time of storage. Stool cultures were performed in all children with diarthea, $B$ cereus being isolated in $39 \%$. No enteropathogenic bacterias were isolated in 16 controls. In order to confirm the source of infection, the enterotoxigenic activity of samples obtained from two formula bottles chosen at random were tested on an animal model (lacrolapinic): 15 strains of $B$. cereus randomly selected were toxic when instilled intragastricolly in suckling mice. Typification of 19 strains was carried out in the Instilute of Public Health in London. Fingland: $99.5 \%$ of them could not be classified by types. This is interpreted as confirming the common source of this outbreak. This is the tirst report of such an outbreak of food poising described in Chile.
\end{abstract}

La presencia de Bacilus cereus en fórmulas infantiles de leche en polvo es un hecho conocido desde principios de siglo; pero recientemente evauado en sus consecuenciast.

Bacillus cereus es un bacilo Gram positivo aerobio y esporogénico que pertenece a la familia Bacillaceae y capaz de desarrollarse en anaerobiosis. Las temperaturas que permiten su proliferación oscilan entre los 10 y los $480^{\circ} \mathrm{C}^{2-3}$.

Esta bacteria se encuentra profusamente difundida en el suelo y se ha podido aistar en casi todos los paises del mundo en una variada gama de alimentos corrientes ${ }^{2-3}$.

Sin embargo, desde 1950 son cada vez más numerosos los trabajos que aportan pruebas fehacientes de la importancia de Bacillus cereus como agente causal de intoxicaciones alimen. tarias $y$ toxiinfecciones en recién nacidos $y$ lactantes ${ }^{2-3-4-5-\grave{b}}$

Goeppert et al. demostraron que Bacillus cereus, produce y segrega por lo menos una en-

1

Médico cirujano, Unidad Microbiologia, Depto. SaIud Pública, Diy. Cs. Med. Oriente, Facultad Medi eina, Universidad de Chilc.

Químico J'armacéutico, Instituto Salud Pública.

3 Médico cirujano, Unidad de Recién Nacidos, Hospital del Salvador. terotoxina durante su desarrollo exponencial en los alimentos ${ }^{3}$.

Aplicando los modelos experimentales de es. tudios de enterotoxigenicidad en Clostridium perfringens, se han liegado a purificar y reconocer en algunas especies de Bacillus cereus dos tipos de enterotoxinas 4-6-7-8.

La más conocida y estudiada es una exotoxina proteica con efecto preferentemente emético (parecida a la enterotoxina del Staphylococcus aureus) que produce un cuadro clínico en el adulto, con un periodo de incubación corto de 1 a 6 hrs.; durando su acción aproximadamente 24 hrs.

La otra denominada esporotoxina por la dependencia a la forma esporulada, es una prote. na susceptible a la acción de la tripsina, termolábil, produce enfermedad en el adulto después de un período de incubación de hasta 12 horas; su acción dura más de 24 horas.

Por un incremento diario de los casos de diarrea aguda en recién nacidos hospitalizados en diferentes salas de la Unidad durante los primeros días del mes de junio de 1981, se planteó la hipótesis de fuente común del brote epidémico.

Este trabajo tiene por objeto describir el brote epidemico de intoxicación alimentaria causada por este microorganismo en la Unidad de Recién Nacidos del Hospital Salvador, ocurrida durante el mes de Julio de 1981 . 


\section{MATERIAL Y METODO}

Se investigó las condiciones higiénico ambientales del Servicio; la manipulación, sistema de preparación, almacenamiento $\mathrm{y}$ distribución de las mamaderas.

El analisis clínico consistió en estudiar la distribución de los casos según sexo, edad gestacional, peso de nacimiento, edad de comienzo del cuadro clínico, dias de evolución, manifes. taciones clínicas y el estado al alta.

Se efectuaron coprocultivos al $1{ }^{\circ}$ y $2^{\circ} \mathrm{d}$ ías de iniciado el cuadro clínico de todos los recién nacidos hospitalizados. Las muestras se sembraron en agar S.S. y Mc. Conkey, agar B.C. y agar Bair Parker, para búsqueda de Salmonella, Shigella, E. coli enteropatógenos clásicos (E.C.E.P.), Staphylococcus aureus y Bacillus cereus.

Para el estudio de Bacillus cereus se sembraron las deposiciones en agar B.C. incubando las placas a $35^{\circ} \mathrm{C}$. por $24-48$ hrs. A 2 ó 3 colonias sospe chosas (forma irregular, lecitinasa $(+)$, manitol ( - ) ) se les efectuó las siguientes pruebas bio. químicas: Fermentación de glucosa, reducción de nitrato a nitrito, hemólisis en agar sangre de cordero, hidrólisis de gelatina y desarrollo en anaerobiosis.

Además, se realizó análisis bacteriológico para pesquisar Salmonella, E. coli, Staphylococcus aureus, Clostridium perfringens y Bacillus cereus de muestras tomadas al azar: envases previamente esterilizados en autoclave en bolsas selladas; envases listos para llenar; leche en polvo en uso (tarros abiertosi y almacenados (tarros sellados) de una misma serie de producción y de diferente procedencia; de otra serie de producción y leche de otras marcas comerciales; endulcorantes (glucosa y nessúcar); mamaderas recién preparadas $y$ de 12 a 24 horas almacenadas en refrigerador; de diferentes muestras ambientales y agua potable de todos los sectores del Servicio. Se investigó la probable existencia de portadores de enteropatógenos entre los manipuladores de alimentos.

Se utilizó el modelo lactolapinico para detectar precozmente actividad enterotoxigénica en 2 mamaderas de 24 horas de almacenadas, elegidas al azar ${ }^{6}$.

De las cepas que dieron las pruebas bioquímicas correspondientes a Bacillus cereus se tomaron las 9 cepas provenientes de coprocultivos $y$ al azar, 2 de leche en polvo y 4 de mamaderas, para estudiar capacidad enterotoxigénica en ratones lactantes ${ }^{6}$.

Ocho cepas de Bacillus cereus aisladas de coprocultivo y 11 aisladas de mamaderas y leche en polvo, que fueron elegidas al azar, fueron enviadas al Instituto de Salud Pública de Londres; Inglaterra, organismo que efectuo la serotipificación ${ }^{22}$.

\section{RESULTADOS}

La figura 1 muestra la incidencia y prevalencia de diarrea aguda en recién nacidos hospitalizados en la Unidad de Neonatología durante el mes de Junio de 1981. Durante los últimos días de Mayo y los primeros del mes de Junio se produjo el punto máximo, con una disminución importante y gradual despues de los cambios efectuados en el sistema de preparación, almacenamiento y distribución de las mamaderas.

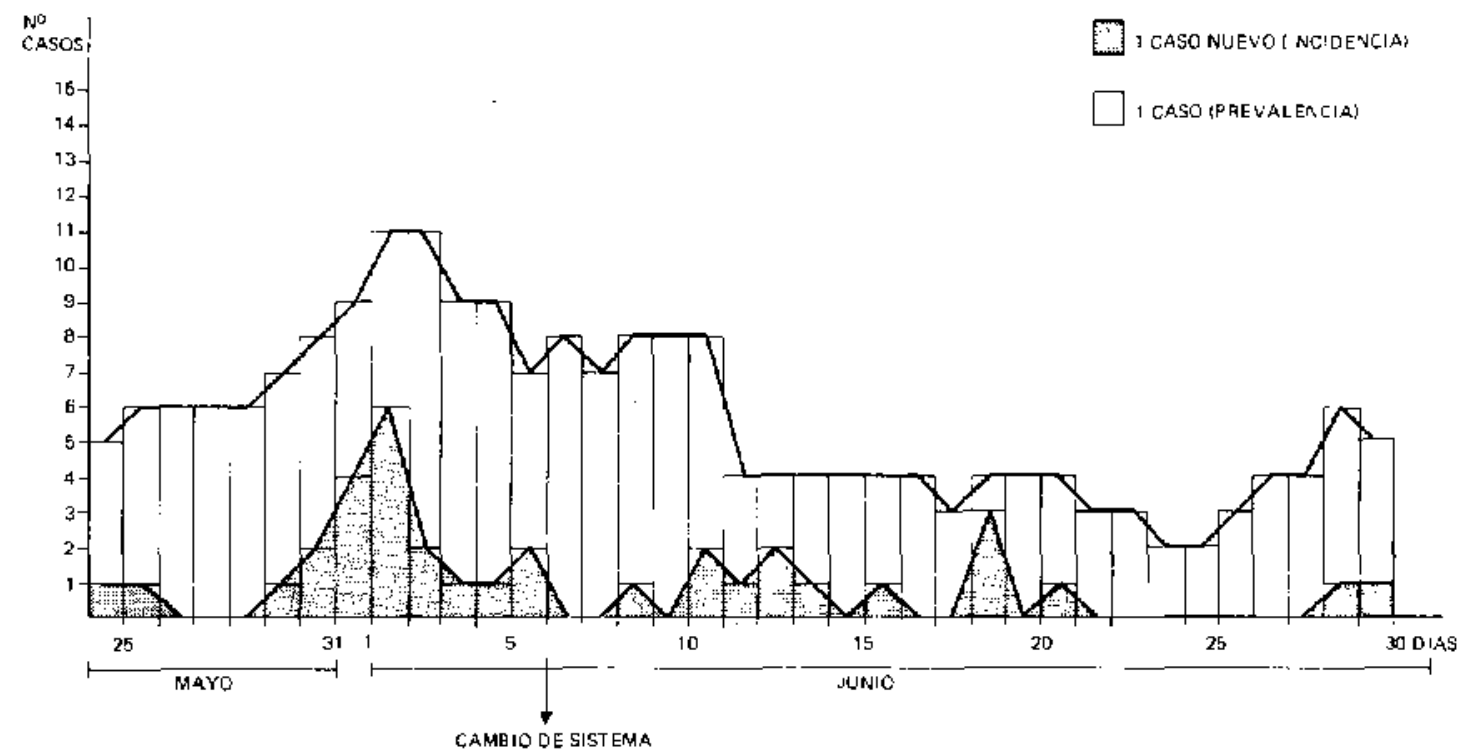

Fig. Incidencia y Prevalencia de Diarrea Aguda en Recién Nacidos Unidad de Neonatologia 1981 
En la tabla 1 están los resultados de los coprocultivos efectuados a los 35 recién nacidos afectados y de 16 recién nacidos elegidos al azar hospitalizados sin diarrea. Vemos que en 9 recién nacidos el único agente' enteropatógeno encontrado fue $B$. cereus y en 4 niños se encontró B. cereus asociados a ECEP 055: B5. Sólo en 2 recién nacidos se encontró como único agente ECEP. De los 16 coprocultivos de los niños sin diarrea no se aisló bacteria enteropatógena.

En tabla 2 abservamos los resultados del estudio bacteriológico efectuado a las leches en polvo. Se puede ver que en un $100 \%$ de los tarros en uso tomados al azar, se encontró $\mathrm{B}$. cereus entre $50-200$ esp/g., en cambio en la leche en polvo de la misma marca pero de otra serie y de leches en polvo de otras marcas, no se encontraron bacterias enteropatógenas.

Tabla 1.

lntoxicación Alimentaria por B, Cereus

Estudà Bacteriológico

\begin{tabular}{|c|c|c|c|c|c|c|c|}
\hline \multirow[t]{2}{*}{ Coprocultivos } & \multirow[t]{2}{*}{ No casos } & \multirow[t]{2}{*}{ B. cereus } & \multirow{2}{*}{\multicolumn{2}{|c|}{$\begin{array}{l}\text { B. cereus E.C.E.P. } \\
+ \\
\text { E.C.E.P. }\end{array}$}} & \multirow[t]{2}{*}{ Otros EP } & \multicolumn{2}{|c|}{$\begin{array}{c}\text { Total } \\
\text { B. cereus }\end{array}$} \\
\hline & & & & & & No & $0 / 0$ \\
\hline R.N. con Diarrea & 35 & 9 & 4 & 2 & 0 & 13 & 37 \\
\hline R.N. sin Diarrea & 16 & 0 & 0 & 0 & 0 & 0 & 0 \\
\hline
\end{tabular}

Tabla 2.

Intoxicación Alimentaria por B. Cereus

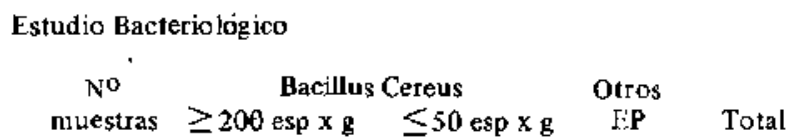

1. Leche en polvo en uso serie " $A$ "

] Sellados

II Abjertos

2. Leche en polvo en uso serie " $\mathrm{B}$ " 1 Sellados II

3. Leche en polvo otras marcas

"C"

"D"

"E"
6

6

6
En la tabla 3 se presentan los resultados del estudio bacteriológico efectuado a las mamade. ras preparadas en el Servicio con la leche en polvo en uso tomadas al azar y de diferentes tiempo de almacenamiento. Se observa que a mayor tiempo de almacenamiento, mayor es el recuento de bacterias por ml. En cambio de las mamaderas elegidas al azar preparadas con la misma leche en polvo, pero de otra serie, no se encontró contaminación bacteriana.

La tabla 4 muestra los resultados obtenidos de las pruebas biológicas de enterotoxigenicidad. Observamos que de 2 mamaderas elegidas al azar, las 2 dieron prueba positiva en modelo lactolapínico. De 15 cepas de B. cereus elegid as igualmente al azar, aisladas de coprocultivos y de leche, todas dieron positiva la prueba de inoculación intragástrica en ratón lactante. 
Tabla 3.

Intoxicación Alimentaria por B. Cereus

Estudio Bacteriológico

\begin{tabular}{cccccccc} 
No & \multicolumn{7}{c}{ Bacillus Cereus: Col x ml } \\
muestras & 50 & 200 & 300 & 500 & 600 & 800 & 20000
\end{tabular}

Mamaderas de leche

Serie "A"

0 horas

12 horas

24 horas

Mamaderas de leche

Serje "B"

6 horas

8
8
8

6

Intoxicación Alimentaria por B. Cereus

Resultados Estudio de Enterotoxigenicidad

Modelo Ratón lac top ínico positivo Lactante positivo

Mamaderas

B. Cereus

$2 / 2$

$15 / 15$

\section{COMENTARIO}

La existencia de intoxicaciones alinentarias por B. cereus en Unidades de Recién Nacidos es un hecho reconocido y descrito en otros países latinoamericanos ${ }^{8-9}$.

El brote de diarrea aguda que se describe en este estudio afectó a 35 recién nacidos de 2 a 92 dias de vida con un promedio de 15 , ingresados por diferentes causas durante el mes de Junio del año 1981; durante este mes se hospitalizaron 117 recién nacidos en la Unidad, por lo que corresponde una tasa de ataque de $29,9^{\circ} / 0$. Todos los niños de esta Unidad recibían alimentación en base a leche en polvo.

Más de] $700 \%$ fueron niños de pretérmino y de término pequeño para la edad gestacional y en un $800 \%$ con peso de nacimiento menor de 2.500 g. por lo cual el grupo afectado está constituido en su mayoría por recién nacidos de bajo peso y de pretérmino constituyendo esto una muestra representativa de los pacientes que se hospitalizan, los cuales dada sus precarias condiciones inmunitarias tienen mayor riesgo de emfermar $y$ como se pudo observar lo hicieron con dosis infectantes inferiores a $10^{6}$ B. Cereus por gramo de alimento, que es la dosis descrita en brotes epidémicos de intoxicación alimentaria en pacientes adultos ${ }^{10}$. Sin embargo, actualmente evidencias que sostienen que $B$, cereus puede

multiplicarse dentro del propio intestino del niño hasta llegar a niveles tales como para producir enfermedad ${ }^{6}$. Ademas del déficit inmunitario propio de los reciên nacidos de pretérmino en nuestros pacientes se agregaron otros factores que entorpecieron en forma importante la evolución de la diarrea, como la patología agregada, la labilidad hidroelectrolítica, su incapacidad de regulación ácido básica. Por todos estos factores observamos que el promedio de duración de la diarrea fue de 8,5 dias, lo cual es notablemente superior a lo que sucede en adultos ${ }^{10}$.

Las manifestaciones clínicas no difieren especialmente de las observadas en diarrea aguda en el recién nacido por otras etilogias; en más de un 800/o de los afectados hubo un cuadro clinico de menos de 15 días de evolución.

Es importante destacar que de los 4 niños fallecidos todos presentaban grave patología asociada, es asi como en 2 de ellos se hizo el diagnóstico de cardiopatia congénita cianótica, uno tenía agenesia del timo y el otro presentó una septicenia por Klebsiella pneumoniae.

Dada la aparición de nuevos casos en điferentes salas se efectuó un estudio dirigido a detectar una fuente de origen comin de la toxinfección. Es así como en el análisis del sistema de preparación y distribución de manaderas se encontraron deficiencias que fundamentalmente consistian en la falta de un esterilizador terminal de mamaderas y el almacenamiento en caliente, en el refrigerador, de todas ellas preparadas para 24 horas, adosadas unas a ot ras, lo que permitia un descenso lento de la temperatura de las leches dentro del refrigerador. En la distribución nuevamente eran calentadas a baño maría y ad. ministradas despues de un promedio de màs o menos una hora.

Estos dos factores facilitan el desarrollo y multiplicación de las esporas de $B$. cereus provenientes de la leche deshidratada y además favore- 
ce la elaboración de una de las enterotoxinas que es una esporotoxina.

Esto se comprobó al analizar el estudio bacteriológico efectuado a la leche en polvo en uso que demostró en el $100 \%$ de las muestras tomadas al azar contaminación con esperas de B. cereus. El estudio de otra serie y de otras marcas fue negativo. Además se demostró un incremento en el recuento de colonias por ml., en las mamaderas preparadas con la leche en polvo contaminada, con mayor tiempo de almacenamiento.

Por otro lado, en 9 de éstos recién nacidos se aisló $B$. cereus de las deposiciones como único agente enteropatógeno, $y$ en 4 de ellos $B$. cereus más E.C.E.P. lo que da un $37 \% \%$ de aislamiento de este agente de las deposiciones, lo cual es sigficativo. Sin embargo, nuestra impresión es que este porcentaje sería inferior a lo real por algunas dificultades técnicas al inicio del estudio como fue el almacenamiento de las muestras, ya que la mayoría de ellas debió permacer más de 10 días para poder procesarlas para estudio deB. cereus.

Además del hecho de comprobar $B$. cereus en la leche en polvo se logró observar actividad enterotoxigénica en el alimento preparado es decir, la mamadera, ya que 2 de ellas elegidas al azar dieron positiva la prueba efectuada en conejo lactante: modelo lactolapínico ${ }^{6}$.

Se observó un descenso importante en la curva de incidencia y prevalecencia de nuevos casos al efectuar cambios en el sistema de preparación y almacenamiento de las mamaderas.

Las 15 cepas de B. cereus de coprocultivos y alimento elegidas al azar dieron la prueba positiva en ratón lactante para el estudio de enterotoxina (esporotoxina). Además, 19 cepas igualmente elegidas al azar, fueron enviadas a la Public Health Laboratory Service de Londres, Inglaterra, organismo que efectuó la serotipificación ${ }^{12}$; donde se demostró que el $99.5 \%$ \% de las cepas estudiadas fueron No tipificables lo cual nos hace suponer el origen de una fuente común de este agente.

Creemos que esta investigación aporta antecedentes xaliosos acerca del rol que juega B. cereus y sus enterotoxinas en la producción de toxiirfecciones gastrointestinales, a través de contaminación de alimentos. Además estos resultados constituyen el primer estudio de un brote de toxiinfección alimentaria por Bacillus cereus en Chile.

\section{RESUMEN}

Durante un brote de diarrea en una Unidad de Neonatología ocurrida en Junio de 1981, que afectó a 35 nif̂ros, se demostró la presencia de $B$. cereus como único agente etiológico.
Se realizaron estudios microbiológicos de la leche en polvo en uso; de la misma leche pero de otras series de producción; y de otras marcas comerciales; tanto en mamaderas recién preparadas como en las almacenadas a $4{ }^{\circ} \mathrm{C}$ después de 12 y 24 hrs., todas elegidas al azar. Se demos. tró la presencia de B. cereus como único agente enteropatógeno en la leche en polvo en uso y en las mamaderas preparadas, con un aumento del recuento a mayor tiempo de almacenamiento. No se encontró B. cereus en las otras leches analizadas.

Se efectuaron coprozultivos en todos los niños con diarrea, aislándose B. cereus en un $37 \%$ o de ellos. No se aislaron bacteriaseenteropatógenas en 16 controles.

Para demostrar el origen alimentario de la toxiinfección se comprobó actividad enterotoxigénica en modelo animal (lactopinico) de 2 mamaderas elegidas al azar. Además se encontró que 15 cepas de B. cereus analizadas igualmente elegidas al azar, eran enterotoxigénas por incoculación intragástrica en ratón lactante. Se serotipificaron 19 cepas en el Instituto de Salud Pública de Londres Inglaterra, siendo el $99.5 \%$ de ellas no tipificables por lo que se comprueba el origen de fuente común de este brote.

Estos resultados constituyen el priner estudio de un brote de toxinfección alimentaria por B. cereus en Chile.

\section{REFERENCIAS}

1 Torres-Angel M.I.: Spore Removal by bactofugation and its effect on the ultra High temperature sterilization of milk. M. Sc. Thesis Michigan State Lniv. East Lausing, Michigan, U.S.A., 1968.

2 Aspectos Microbiológicos de la higiene de los alimentos. Informe del Comité de Expertos de la OMS. Serie de Informes Técnicos No 598, pág. 32-36. Gi nebra 1976.

${ }^{3}$ Goeppert J.M., Spira W.M. and Kim H.U.: Bacilbs cereus: Jood Poisoning Organism: A review J. Milk. Food Technol Vol. 35:213-227, 1972

4 Terranova $W$, Blake P.A,: Bacillus cereus food Poisoning. N. Engl. J. Med. 298: 143, 1978.

5 Gianella R.A., Brasile L,: A Hospital Irood-Borne outbreak of Diarshea caused by Bacillus cereus: Clinical, Epidemiologic, and Microbiologic Studies, J. Infect Dis. 139: 366, 1979.

6 Torres-Angel J.M., González G.H., Giraldo M.E., Obivera Angel $M$. . Camacho A., Segura $C$.: Enterotoxigenictdad de Bacillus cereus. Rev. Lat Amer. Microbiol. 21: 66, 1979.

${ }^{7}$ Tumbull P.C.B., Nottingam J.F., Ghosh A.C.: A severe Necrotic enterotoxin produced by certain food poisoning and other clinical isolated of $B$. cereus. Brit. J. Exp. Path. 58: 273, 1977.

8 Torres-Angel M.J., Gonzdlez G.H., Giraldo M.E, $y$ Oliera $M_{*}$ : Enterotoxigenicidad de Bacillus cereus implicado en un brote de Mortalidad Neonatal en Medellín, Colombia. Bol. Epid. Nac. (Minsalud, Bogotá, DE). 3: 30, 1977. 
${ }^{9}$ González G. et al: Intoxicación alimentaria por Bacillus cereus en el Servicio de Neonatología del Hospital General de Medellín. Bol. Epidemiol Nac. (Mínsalud, Bogotá D.E.) 3: 13, 1977.

10 Gitbert R.J." Taylor A.J.: Bacillus cereus rood Poisening. Microbiology in Agriculture, Fisheries and Food. Socjety for Applical Bacteriology. Symposium Series No 4, London, 1976.
11 Mayorga C.I., Torres-Angel M.J., Figueroa J.: Caracterización de una fracción proteica que cromatográficamente antecede a la esporo-(entero)-toxina de Clostridium perfringens (Welchii). Rev. Lat. Amer. Microbiolog. 20: 13, 1978.

12 Gilbert R.J., Parry M.J.: Serotypes of Bacillus cereus from out Break of Food Poisoning and from Routine Fonds. Journal of Hqgiene 78: 69, 1977. 